${ }^{1}$ Departement of Restorative and Aesthetic Dentistry, School of Dentistry. Saint Joseph University, Beirut, Lebanon.

${ }^{2}$ Department of Prosthodontics, Lebanese University, Beirut, Lebanon.

${ }^{3}$ Histology Lab Technician, Saint Joseph University, Beirut, Lebanon.

${ }^{4}$ Departement of Pathology, School of Dentistry. Saint Joseph University, Beirut, Lebanon.

${ }^{5}$ Departement of Periodontology, School of Dentistry. Saint Joseph University, Beirut, Lebanon.

Corresponding author: Corresponding Dr Cynthia Kassis cynthiakassis@usj.edu.lb, Beirut, Lebanon, 9613782588

Editor: Altair A. Del Bel Cury

Received: January 03, 2021

Accepted: August 12, 2021

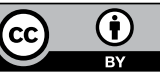

\section{Response of dental pulp capped with calcium-silicate based material, calcium hydroxide and adhesive resin in rabbit teeth}

\author{
Cynthia Kassis $^{1 *}$ (D), Pierre Khoury ${ }^{2}$ (D) Karim Corbani ${ }^{1}$, \\ Charbel Mansour ${ }^{3}$, Louis Hardan', Ghassan Yared ${ }^{4}$, \\ Carole Chakar $^{5}$ (D)
}

Direct pulp capping induces a local inflammatory process. Several biomaterials have been used for this procedure. The aim of this study was to compare the dentinal bridge thickness using three different pulp capping biomaterials with the conventional technique (high speed diamond bur) or Er-Yag laser, 1 month after pulp effraction. Materials and Methods: Forty two Class $\checkmark$ cavities were prepared on the buccal surface of 4 maxillary incisors and 2 mandibular incisors of New Zealand rabbits. Specimens were divided into 6 treatment groups. Teeth were treated with: In Group 1: Er-Yag laser and Biodentine ${ }^{\circledR}$ (Septodont), in Group 2: Er. Yag laser and calcium hydroxide (Dycal® Dentsply), in Group 3: Er: Yag laser and adhesive system (Prime\& Bond $\circledast$ NT Dentsply), in Group 4: high speed diamond bur and Biodentine ${ }^{\circledR}$ (Septodont), in Group 5: high speed diamond bur and calcium hydroxide (Dycal ${ }^{\circledR}$ Dentsply), and in Group 6: high speed diamond bur and adhesive system (Prime\& Bond ${ }^{\circledR}$ NT Dentsply). The preparation was done with copious irrigation. The animals were sacrificed at 30 days and the teeth were extracted and prepared for histological analysis. Results: In the group of « laser Er-Yag ", iatrogenic pulpal wounds treated with Biodentine ${ }^{\circledR}$ were covered with a thick hard tissue barrier after 1 month. The difference was not significant with the groups of Dycal ${ }^{\circledR}$ used with Er: Yag laser and high speed diamond bur. Prime\& Bond® NT Dentsply specimens showed a thin dentinal bridge layer. Conclusion: At 1 month, Er-Yag laser proved to be useful with Biodentine ${ }^{\circledR}$ for direct pulp capping procedures.

Keywords: Dental pulp capping. Lasers. Lasers, solidstate. Calcium compounds. Silicates. Calcium hydroxide. Polymethacrylic acids. 


\section{Introduction}

Direct pulp capping is a procedure defined to cover an exposed pulp by a biocompatible material to promote dentinal bridge formation. The biocompatibility or inflammatory effects of pulp capping materials are important to avoid pulp tissue irritation or degeneration'. Direct pulp capping therapies use biomaterials to protect exposed tissues, inducing repair through the production of a mineralized barrier $^{2}$. This procedure induces a local inflammatory process leading to pulp cells recruiting. They proliferate and differentiate into odontoblast cells that produce an extracellular matrix which turns out to be a scaffold for a mineralized dentinal reparative bridge ${ }^{3}$.

Calcium Hydroxide $(\mathrm{Ca}(\mathrm{OH}) 2)$ has been considered as the material of choice for direct pulp capping. It showed good biocompatibility properties with the dental pulp tissue, inducing the expression of reparative molecules ${ }^{4}$. Despite its low-grade irritation of the traumatized pulp tissue, $\mathrm{Ca}(\mathrm{OH}) 2$ showed disadvantages including gradual degradation, tunnel defects in dentinal bridge and poor sealing properties ${ }^{5}$. These clinical characteristics have encouraged the development of several other materials for direct pulp capping ${ }^{6}$.

Biodentine ${ }^{\circledR}$ is made up predominantly of highly purified tricalcium silicate $(80.1 \%)$ as the main core material, calcium carbonate (14.9\%) as a filler, and zirconium oxide (a radioopacifier) ${ }^{7}$. With active technology. It can be used not only as an endodontic repair material but also as a coronal restorative material for dentin replacement. It is a restorative cement with dentin-like mechanical properties that can be used as a dentine substitute on crowns and roots. It has a positive effect on vital pulp cells and stimulates tertiary dentin formation ${ }^{8}$. Direct pulp capping with adhesive systems is still a controversial subject. Several studies was done to investigate the effect of adhesive systems on direct pulp capping ${ }^{9}$. Laser technology proved effective in improving the prognosis of pulp capping procedures on teeth affected by deep caries pathology. Lasers for pulp capping have advantages such as disinfecting and coagulative properties ${ }^{10}$.

The aim of this study was to compare the dentinal bridge thickness using three different pulp capping biomaterials with the conventional technique (high speed diamond bur) or Er-Yag laser, 1 month after pulp effraction.

\section{Materials and methods}

\section{Surgical procedure}

This study was approved by the ethical committee at Saint Joseph University, Lebanon

A total of 42 healthy, mature, permanent maxillary and mandibular incisor teeth of 7 New Zealand rabbits (3.5-4 kg weight) were included in the study (Fig. 1).

The animals were anesthetized by intraperitoneal injection of a combination of ketamine (Imalgene 500, Merial, France) (50mg/ml) and xylazine (Rompun, Bayer, France)

$(25 \mathrm{mg} / \mathrm{ml})$. 
42 Class $V$ cavities were prepared in the cervical buccal surface of 4 maxillary incisors and 2 mandibular incisors. They were divided into 2 groups according to the technique of the cavity preparation.

- In the first group, 21 class $\vee$ cavities were prepared with an exposure zone in the center of each cavity using a high-speed round diamond bur $(0.2 \mathrm{~mm})$ without excessive pressure and with copious irrigation (Fig 2).

- $\quad$ In the second group, 21 cavities were prepared and pulps were exposed by a 0.2 tip of Er-Yag laser irradiation at an energy level of $200 \mathrm{~mJ}$, a frequence of $15 \mathrm{~Hz}$, with $4 \%$ water and 6\% air (Fig 3).

Following immediately the exposure, the cavities were washed with sterile $0.9 \%$ normal saline and capped with 3 different materials. The capping biomaterials were used according to the manufacturer's instructions:

- $\quad$ Biodentine ${ }^{\circledR}$ (Septodont).

- $\quad$ Calcium hydroxide, $\mathrm{CH}$ paste $\left(\right.$ Dycal $\left.^{\circledR}\right)$.

- $\quad$ Adhesive system (Prime\&Bond $\mathrm{NT}^{\circledR}$ Dentsply).

Specimens were divided into 6 treatment groups:

Groupe 1: teeth were treated with Erbium:YAG laser and Biodentine ${ }^{\circledR}$ Septodont.

Groupe 2: teeth were treated with Erbium:YAG laser and self-hardening calcium hydroxide (Dycal ${ }^{\circledR}$ Dentsply).

Groupe 3: teeth were treated with Erbium:YAG laser and adhesive system (Prime\&Bond $\mathrm{NT}^{\circledR}$ Dentsply).

Groupe 4: teeth were treated with high speed diamond bur and Biodentine ${ }^{\circledR}$.

Groupe 5: teeth were treated with high speed diamond bur and self-hardening calcium hydroxide (Dycal ${ }^{\circledR}$ Dentsply).

Groupe 6: teeth were treated with high speed diamond bur and adhesive system (Prime\&Bond $\mathrm{NT}^{\circledR}$ Dentsply).

All cavities were subsequently filled with a bulk- fill flowable composite SDR (DENTSPLY) and covered by Esthet-X composite DENTSPLY

This study involves two treatment steps: the first step involves preparation of the exposed pulp tissue and the surrounding dentin, whereas the second step consists of sealing the exposed pulp with one of the mentioned dental materials

The animals were sacrificed at 30 days using anesthetic overdose and the incisors were extracted and prepared for histological examination and evaluation.

A histological procedure for non- demineralized bone was used for all excised tissue specimens. Each tooth specimen was fixed in $10 \%$ phosphate-buffered formalin, rinsed in water, dehydrated in ethanol, cleared in xylene, and embedded in methylmethacrylate. 
Sections of the fixed teeth were cut parallel to the sagittal plane. Each section was then ground down to a thickness of $100 \mu \mathrm{m}$, using the Exact Grinding System (Exact Aparatebau GmbH Norderstedt, Germany) and polished down to $70 \mu \mathrm{m}$. These specimens were stained with hematoxylin and eosin staining before visualisation under standard light microscopy. Histomorphometric analysis was performed using a lightmicroscope (Olympus Bx 4500) linked to a digital camera (Nikon Coolpix 4500) equipped with a video and image analysis system (System Supply Co. Ltd., Ina, Japan). The histomorphometric data of three sections from each specimen were extracted using the UTHSCA Image Tool 3.0 software. One measurement was taken in the middle of the dentinal brige and the other two were evaluated at two equidistant points. Each image was filtered and the pixels belonging to mineralized tissue and to residual material were identified, delineated manually. The areas of newly formed dentinal bridge and inflammatory cell response as presence or absence of each image were quantified.

\section{Statistical analyses}

The data collected from the histological examinations were statistically analyzed using the SPSS for Windows version 18.0. The alpha error was set at 0.05. The outcome variable of the study was the dentinal bridge thickness.

The Kolmogorov-Smirnov tests were used to assess the normality of the distribution of variable.

Kruskal-Wallis tests followed by multiple comparisons tests after adjustment or type I error were used to compare the dentinal bridge thickness between Biodentine ${ }^{\circledR}$, Dycal $^{\circledR}$ and adhesive system. Mann-Whitney tests were used to compare the primary outcome variable between laser and conventional technique. The P-value was considered significant.

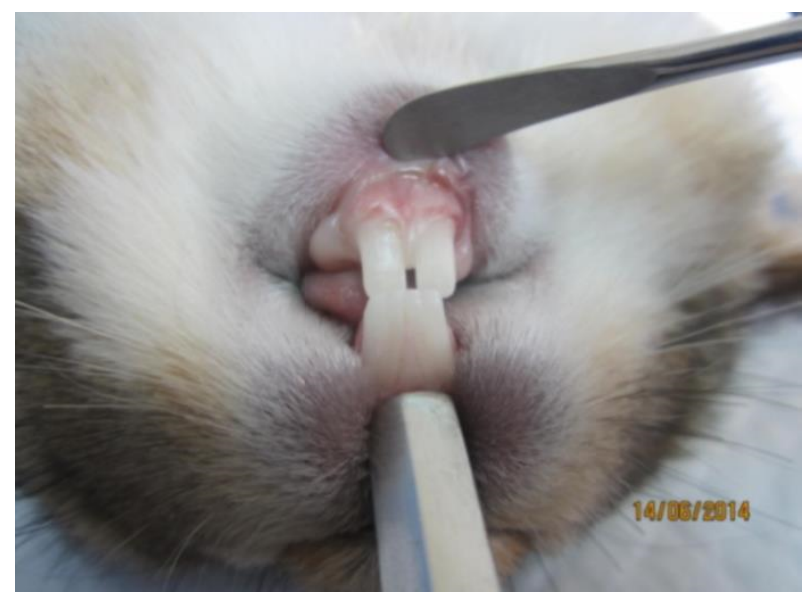

Figure 1. Permanent maxillary and mandibular incisor teeth of New Zealand rabbits 


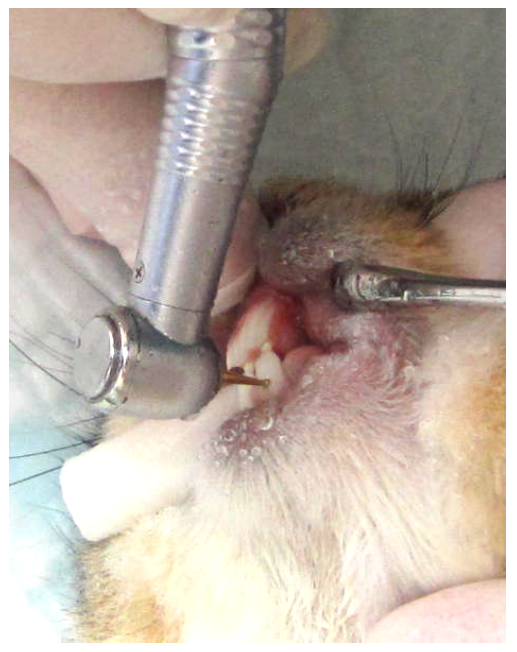

Figure 2. Pulp exposure with rotating instruments

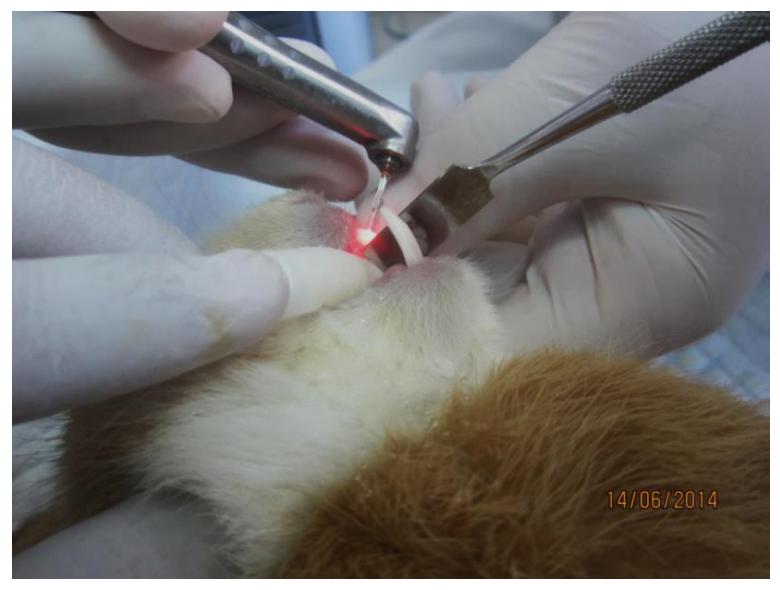

Figure 3. Pulp exposure with Er-YAg laser

\section{Results}

Two rabbits were lost after 2 weeks of the treatment

\section{Histological observations}

Most of specimens showed after 4 weeks of dental pulp capping complete dentinal bridge formation and absence of inflammatory cells. However, we find abundant inflammatory cells in teeth prepared with the conventional technique and capped with the adhesive system (Fig 4).

\section{Histomorphometric observations}

After 4 weeks of pulp capping, histological analysis of sections of the excised specimens provided evidence that all the teeth showed a dentinal bridge formation in continuity with the residual dentin in either the absence or presence of inflammatory cells (Fig 4).

The newly formed dentinal bridge in contact with the pulp exposure appeared mature.

The thickness of the dentinal bridge using the high speed diamond bur was significantly higher with Biodentine ${ }^{\circledR}$, intermediate with Dycal ${ }^{\circledR}$ and smaller with adhesive system (-p-value $<0.0001)$.

When using the laser Er/Yag technique, the thickness of the dentinal bridge was significantly higher with Biodentine ${ }^{\circledR}(-p-$ value $<0.0001)$. No significant difference was found between Dycal ${ }^{\circledR}$ and the adhesive system at 1 month when using Laser Er-Yag $(-p$-value $=0.117)$. 

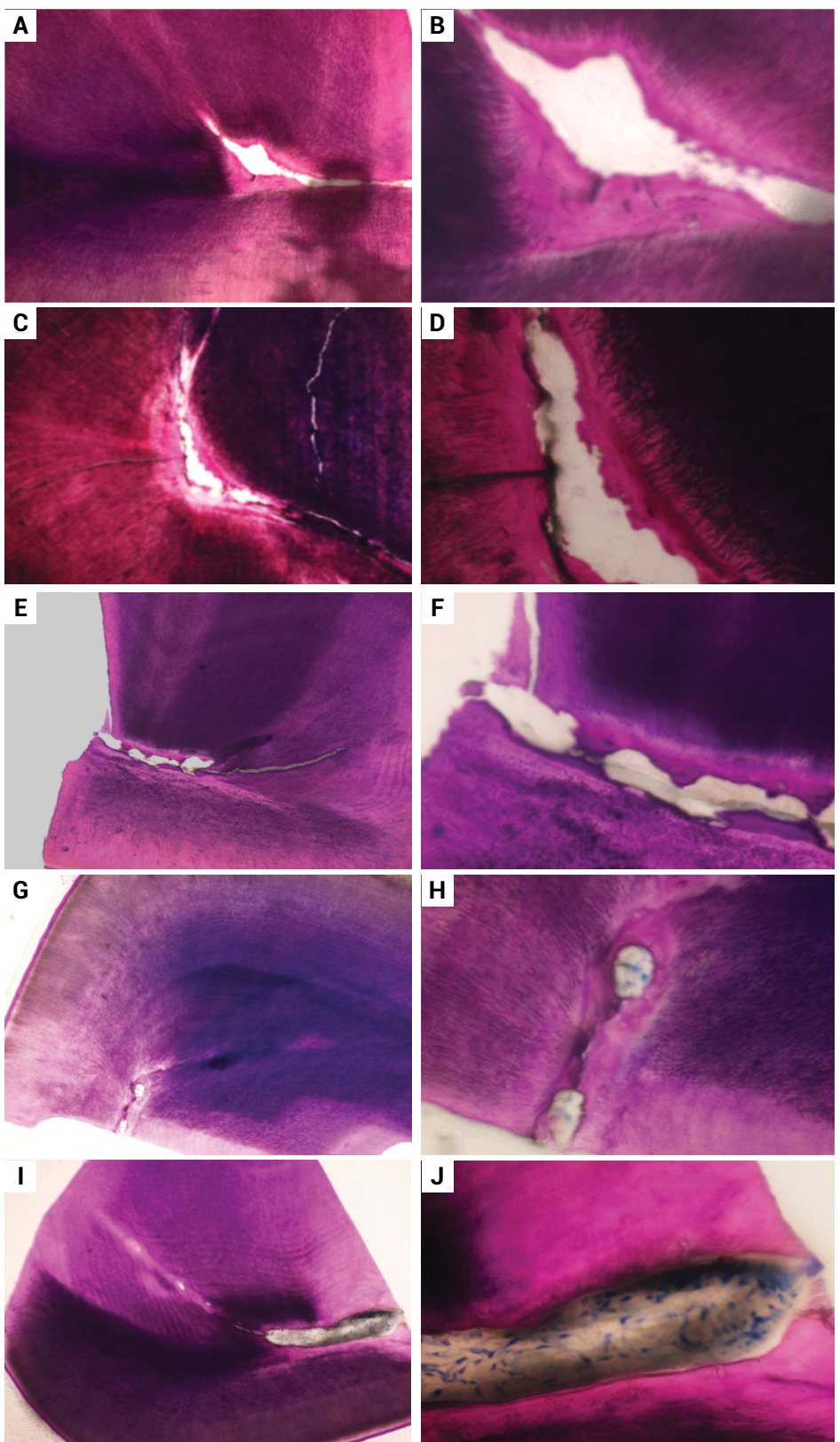

a. Teeth treated with Erbium:YAG laser and Biodentine ${ }^{\circledR}$ (magnification $\left.\times 10\right)$; b. Teeth treated with Erbium:YAG laser and Biodentine ${ }^{\circledR}$. (magnification $\times 40$ ); c. Teeth treated with traditional rotating instruments and Biodentine ${ }^{\circledR}$ : Formation of a thick calcified bridge at pulp- Biodentine ${ }^{\circledR}$ interface. (magnification $\times 10$ ); $d$. Teeth treated with traditional rotating instruments and Biodentine ${ }^{\circledR}$ : Formation of a thick calcified bridge at pulp-Biodentine ${ }^{\circledR}$ interface (magnification $\times 40$ ); e. Teeth treated with Erbium:YAG laser and self-hardening calcium hydroxide (Dycal ${ }^{\circledR}$ Dentsply): Formation of a thick calcified bridge at pulp- Dycal ${ }^{\circledR i n t e r f a c e ~(m a g n i f i c a t i o n ~} \times 10$ ); f. Teeth treated with Erbium:YAG laser and self-hardening calcium hydroxide (Dycal ${ }^{\circledR}$ Dentsply): Formation of a thick calcified bridge at pulp- Dycal ${ }^{\circledR i n t e r f a c . ~(m a g n i f i c a t i o n ~} \times 40$ ); g. Teeth treated with Erbium:YAG laser and adhesive system (Prime\&Bond NT ${ }^{\circledR}$ Dentsply).(magnification $\left.\times 10\right)$; $h$. Teeth treated with Erbium:YAG laser and adhesive system (Prime\&Bond NT ${ }^{\oplus}$ Dentsply). (magnification $\times 40$ ); i. Teeth treated with traditional rotating instruments and adhesive system (Prime\&Bond NT ${ }^{\oplus}$ Dentsply): Formation of a thin calcified bridge at pulp- Prime\&Bond NT ${ }^{\circledR}$ interface with the presence of inflammatory cells. (magnification $\times 10$ ); j. Teeth treated with traditional rotating instruments and adhesive system (Prime\&Bond $N T^{\circledR}$ Dentsply): Formation of a thin calcified bridge at pulp-Prime\&Bond NT ${ }^{\circledR}$ interface with the presence of inflammatory cells (magnification $\times 40$ )

Figure 4. Light micrographs illustrating details of the dentinal bridge formation after 4 weeks of dental pulp capping using different technique and different biomaterials. 


\section{Comparison between techniques}

The thickness of the dentinal bridge was significantly higher with Biodentine ${ }^{\circledR}$ associated with laser Er/Yag compared to Biodentine ${ }^{\circledR}$ associated with high speed diamond bur $(-p$-value $=0.020)$.

The difference was not significant between laser Er/Yag and conventional technique $(-p$-value $=0.244)$ with Dycal ${ }^{\circledR}$.

The thickness of the dentinal bridge was significantly higher with adhesive system associated with laser compared to adhesive system associated with high speed diamond bur (-p-value <0.0001) (Table 1, Fig 5).

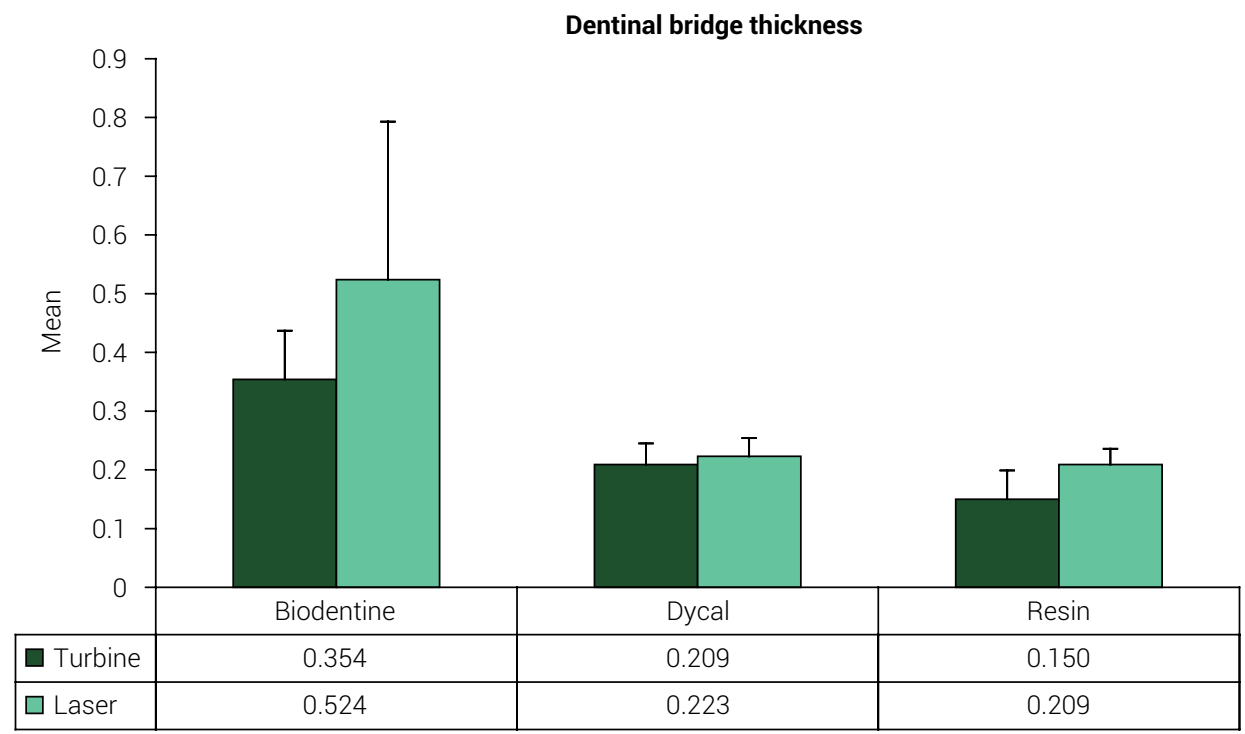

Figure 5. Dentinal bridge thickness among different groups

Table 1. Dentinal bridge thickness among different groups

\begin{tabular}{|c|c|c|c|c|}
\hline \multicolumn{5}{|c|}{ Dentinal bridge thickness } \\
\hline & Biodentine $^{\circledR}$ & Dycal $^{\circledast}$ & adhesive system & -p-value \\
\hline Turbine Mean \pm Standard-deviation & $\begin{array}{c}0.354 \pm 0.083 a \\
N=18\end{array}$ & $\begin{array}{c}0.209 \pm 0.036^{b} \\
N=15\end{array}$ & $\begin{array}{c}0.150 \pm 0.049^{\circ} \\
N=18\end{array}$ & $<0.0001$ \\
\hline Laser Mean \pm Standard-deviation & $\begin{array}{c}0.524 \pm 0.269^{d} \\
N=18\end{array}$ & $\begin{array}{c}0.223 \pm 0.031^{\mathrm{e}} \\
\mathrm{N}=18\end{array}$ & $\begin{array}{c}0.209 \pm 0.027^{\mathrm{e}} \\
\mathrm{N}=18\end{array}$ & $<0.0001$ \\
\hline $\mathrm{p}$-value & 0.020 & 0.244 & $<0.0001$ & \\
\hline
\end{tabular}

\section{Discussion}

The purpose of this study was to compare the thickness of the dentinal bridge following a pulp effraction using the Er-Yag laser and the conventional technique (high speed diamond bur) with 3 different biomaterials: Biodentine ${ }^{\circledR}$, Dycal ${ }^{\circledR}$ and Prime \& 
Bond ${ }^{\circledR}$ NT Dentsply. The results have rejected the null hypothesis. Biomaterials and techniques have affected the thickness of dentinal bridge.

The direct pulp capping aimed to preserve the vitality of the dental pulp after pulp exposure. This involves applying a biomaterial to direct contact with a pulpal wound, in order to promote its healing and obliteration by a newly formed dentine bridge?

The role of the biomaterial is to protect and isolate the pulp from percolation and to induce its healing by an anti-inflammatory action, or even by the induction of its dentinogenetic activity.

The success of this treatment is ensured under defined conditions: symptoms- free tooth, technical procedure and the choice of the biomaterials ${ }^{11}$.

Different studies have put the light on the variation of the results and the success rate of the direct dental pulp capping when using different materials.

We have used the Calcium hydroxide because it was the gold standard material due to its biocompatibility, highly alkaline $\mathrm{pH}$, bactericidal effect and capability to induce tertiary dentin formation ${ }^{3}$. This material created an alkaline environment favorable to the formation of dentinal bridge ${ }^{4}$.

It presents some disadvantages, as has been widely reported: poor adherence to dentin, dissolution over time, and multiple tunnel defects in the formed dentin bridges 5 .

Many studies have been done to find a good substitute to $\mathrm{Ca}(\mathrm{OH})_{2}$ as a pulp-capping agent. Some authors tested another biomaterial for dental pulp capping: Biodentine. It is a calcium silicate-based restorative cement with dentine-like mechanical properties. In direct contact with vital pulp tissue, it also promotes the formation of reparative dentine ${ }^{6}$. This material is a bioactive tricalcium silicate (Biodentine ${ }^{\circledR}$, Septodont); it was introduced for use in vital pulp therapy for direct pulp capping, pulpotomy, and indirect pulp capping. Biodentine ${ }^{\circledR}$ has demonstrated bioactivity and formation of apatite. A specific characteristic of Biodentine ${ }^{\circledR}$ is its ability to continue to improve its mechanical strength over time for several days until reaching $300 \mathrm{MPa}$ after 1 month. This process may be related to decreased porosity over time. This increase in the cohesion of the crystals formed in contact with the material could create a micro-anchorage, responsible for the good adhesion of the biomaterial

In our study, the thickness of dentinal bridge at 1-month was significantly higher following the use of Biodentine ${ }^{\circledR}$ and was intermediate with Dycal ${ }^{\circledR}(-p-$ value $<0.0001)$. In fact, Zaen El Din et al. ${ }^{7}$ (2020) showed that The results related to Biodentine revealed that this material could induce thicker dentinal bridges than MTA and nHap, a nano-hydroxyapatite material.

Although the thickness of the dentinal bridge was significantly higher with the use of Er-Yag laser with Biodentine ${ }^{\circledR}(-p-v a l u e<0.0001)$, the difference was not significant when using Dycal ${ }^{\circledR}(-p$-value $=0.117)$.

The results obtained with $\mathrm{Dycal}^{\circledR}$ are similar to the results of the study which showed that the formation of a dentinal bridge following the use of Dycal ${ }^{\circledR}$ as a pulp capping biomaterial can only be obtained after 3 months of the direct pulp capping. Similarly, Olsson et al. ${ }^{8}$ in 2006, concluded that there is no hard tissue barrier reported in stud- 
ies of less than 3 weeks and the general dynamics of neo-formed dentin production will follow direct pulp capping using calcium hydroxide. This neo-formed dentine is characterized by continuous production but in a variable level over time. Indeed, at three months, the thickness of neo-formed dentin is generally thin and for such low dentinal thicknesses, reopening before 6 months constitutes a risk of bacterial contamination. In the 1-month period the cessation of the inflammatory phase and tissue organization was observed in some groups. The repair mechanism by deposition of mineralized tissue depends on the $\mathrm{pH}$ and the ability of tricalcium silicate cement to release various ions ${ }^{5}$.

A pulp capping is successful if a dentinal bridge is formed between the remaining pulp and the biomaterial: calcium hydroxide has been 100\% successful. However, Barrieshi-Nusair and Qudeimat ${ }^{10}$ in 2006, showed that the thickness of the dentine bridge formed with MTA ${ }^{\circledR}$ is greater than that formed by calcium hydroxide. And After 36-month follow-up, both MTA+ and Biodentine were found to be the appropriate material for direct pulp capping in permanent teeth. The non-adhesion of calcium hydroxide to dentin and its low mechanical properties make it necessary to apply it in a thin layer and to think that calcium hydroxide does not prevent micro-percolation ${ }^{10}$.

Nielsen et al. ${ }^{12}$ (2016), have studied the compressive strength of 4 biomaterials: TheraCal ${ }^{\circledR}$, Biodentine ${ }^{\circledR}$, mineral trioxide aggregate $\left(\mathrm{MTA}^{\circledR}\right)$ and calcium hydroxide after 15 minutes, 3 hours, and 24 hours. After 3 hours, Biodentine ${ }^{\circledR}$ had greater stiffness after 3 hours to potentially provide better support of an overlying restoration under function over time. Kim et al. ${ }^{13}$ (2016) showed that calcium silicate-based pulp-capping materials induce favorable effects on reparative processes during vital pulp therapy.

The formation of a regular and dense dentinal bridge is histologically demonstrated in less than a month. After 1 month, the dentine bridge formed with Biodentine ${ }^{\circledR}$ was denser than that formed with calcium hydroxide.

Laurent et al. ${ }^{11}$ (2012) has described the ability of the tricalcium silicate-based cement to induce reparative dentin synthesis by modulating pulp cells to secrete TGF-ß1 and stimulate dental pulp. The key of success for the biological tooth treatment lies in the isolation of the pulpo-dentinal complex and the adaptation of pulp capping materials. One of the main factors that can compromise this healing are bacterial infiltrations through the restoration interface. Stefanova et al. ${ }^{14}$ in 2015 have demonstrated that the dentin surface prepared with Er-Yag laser showed a very good adaptation of the tested pulp capping biomaterials which ensured a log term prognosis ${ }^{14}$.

Furthermore, Nammour et al. ${ }^{15} 2009$ concluded that laser in direct pulp capping increases significantly the percentage of pulp vitality preservation and the thickness of the dentinal bridge newly formed. In this study the results obtained in the "Er-Yag laser" groups were better than those of the conventional technique (high speed diamond bur) groups: the thickness of the dentine bridge was significantly higher with Biodentine ${ }^{\circledR}$ and the Er-Yag laser than that obtained with Biodentine ${ }^{\circledR}$ and conventional technique. In fact, Er- Yag laser ensured the sterilization of the surface and a very good adaptation of the restoration.

Similarly, the thickness of the dentine bridge was significantly higher when using the Prime \& Bond ${ }^{\circledR}$ NT Dentsply associated with the Er-Yag laser compared to the Prime 
\& Bond ${ }^{\circledR}$ NT Dentsply associated with the conventional technique. However in both cases, we have noticed the presence of inflammatory cells at 1 month but in less quantity when using the laser Er- Yag (Fig4).

Studies concerning the use of adhesive systems in dental pulp capping are controversial. In our study, the results showed that adhesive system showed a thin newly formed dentinal bridge.

In fact, da Silva et al. ${ }^{16}$ in 2009, has evaluated the pulp response following direct pulp capping by the "all-in-one self-etching adhesive system" in dogs' teeth. Their results showed that this biomaterial did not stimulate the formation of the dentinal bridge in $100 \%$ of the cases. However, Lu et al. ${ }^{17}$ have shown that the adhesive system is biocompatible with the pulp tissue, but its ability to induce the formation of dentinal bridge was significantly lower than with calcium hydroxide. It has been reported that the hybrid layer formed with the latest-generation adhesive systems is able to prevent the penetration of bacteria and their byproducts, fluids, and chemical substances, which would justify their use as pulp-capping agents therefore the damage to the pulp tissue after adhesive restorations is due to bacterial leakage and not to an adverse effect induced by the chemical composition of the resin materials ${ }^{18}$.

\section{Conclusion}

Pulp capping represents the boundary between conservative and endodontic therapy. Recent research in this vision will encourage practitioners to consider pulp capping as the first therapeutic approach to pulpal recovery.

Based on this study's results, the following conclusions can be made:

- $\quad$ The 3 biomaterials were able to stimulate hard tissue formation at different diameters after a direct pulp capping in noncarious permanent rabbit teeth.

- The laser Er-Yag stimulated the dentinal bridge formation.

- Dental pulp stem cells (DPSCs) and Stem cells from Human Exfoliated Deciduous Teeth (SHED) have been identified as a novel tool that have the capacity of self-renewel and multi lineage differentiation. This new direct pulp-capping technique promises as a potential alternative to conventional materials for direct pulp capping.

The long-term effect of direct pulp capping and pulpotomy is closely related to the type of pulp capping materials ${ }^{19}$. Recent advances in bioactive materials and those derived from MTA have shown promising results that could improve biomaterials used in vital pulp treatments ${ }^{20}$ it would allow investigating the modulatory effects of newly released pulp capping materials on the balance between tissue inflammation and regeneration ${ }^{21}$. The tailored amorphous multi-porous (TAMP) material fabrication technology has led to a new class of bioactive materials possessing versatile characteristics. mini-swine dental pulp stem cells (DPSCs) in vitro and with pulp in vivo, it may help regenerate the dentin bridge after pulp exposure ${ }^{22}$. Pure calcium-hydroxide powder/saline and the commercial resin-free hydraulic calcium-silicate cement Pro-Root MTA (Dentsply-Sirona) are the best options to provide a complete reparative bridge upon vital pulp therapy ${ }^{23}$. 
Clinical significance: In deep cavities, the treatment of choice will be the pulp capping in vital pulp to promote the cicatrisation and the dentinal bridge formation. In fact, Alex has described how to manage a mechanical vital pulp exposure that occurred during deep caries excavation ${ }^{24}$. There is a need to improve knowledge and attitude of dental professionals about the Vital Pulp therapy ${ }^{25}$. The pulp capping treatment should be done when the clinical symtoms are absent because there is a correlation between the clinical symptoms/signs and pulp sensibility testing and the histological findings of the pulp ${ }^{26}$.

\section{Acknowledgments}

We gratefully acknowledge the help of Dr. Nada El Osta for her help with the statistical analysis. This study was funded by, Saint-Joseph University, School of Dentistry, Beirut, Lebanon

\section{References}

1. Akhlaghi $\mathrm{N}$, Khademi A. Outcomes of vital pulp therapy in permanent teeth with different medicaments based on review of the literature. Dent Res J (Isfahan). 2015 Sep-Oct;12(5):406-17. doi: 10.4103/1735-3327.166187.

2. Boutsiouki C, Frankenberger R, Krämer N. Relative effectiveness of direct and indirect pulp capping in the primary dentition. Eur Arch Paediatr Dent. 2018 Oct;19(5):297-309. doi: 10.1007/s40368-018-0360-x.

3. Andrei M, Vacaru RP, Coricovac A, Ilinca R, Didilescu AC, Demetrescu I. The effect of calcium-silicate cements on reparative dentinogenesis following direct pulp capping on animal models. Molecules. 2021 May 6;26(9):2725. doi: 10.3390/molecules26092725.

4. Brizuela C, Ormeño A, Cabrera C, Cabezas R, Silva Cl, Ramírez V, et L. Direct pulp capping with calcium hydroxide, mineral trioxide aggregate, and biodentine in permanent young teeth with caries: a randomized clinical trial. J Endod. 2017 Nov;43(11):1776-80. doi: 10.1016/j.joen.2017.06.031.

5. Paula AB, Laranjo M, Marto CM, Paulo S, Abrantes AM, Casalta-Lopes J, et al. Direct pulp capping: what is the most effective therapy?-systematic review and meta-analysis. J Evid Based Dent Pract. 2018 Dec;18(4):298-314. doi: 10.1016/j.jebdp.2018.02.002.

6. Jalan AL, Warhadpande MM, Dakshindas DM. A comparison of human dental pulp response to calcium hydroxide and Biodentine as direct pulp-capping agents. J Conserv Dent. 2017 Mar-Apr;20(2):129-33. doi: 10.4103/0972-0707.212247.

7. Zaen El-Din AM, Hamama HH, Abo El-Elaa MA, Grawish ME, Mahmoud SH, Neelakantan P. The effect of four materials on direct pulp capping: An animal study. Aust Endod J. 2020 Aug;46(2):249-56. doi: 10.1111/aej.12400.

8. Olsson $\mathrm{H}$, Petersson $\mathrm{K}$, Rohlin M. Formation of a hard tissue barrier after pulp cappings in humans. A systematic review. Int Endod J. 2006 Jun;39(6):429-42. doi: 10.1111/j.1365-2591.2006.01116.x.

9. Peskersoy C, Lukarcanin J, Turkun M. Efficacy of different calcium silicate materials as pulp-capping agents: Randomized clinical trial. J Dent Sci. 2021 Mar;16(2):723-31. doi: 10.1016/j.jds.2020.08.016.

10. Barrieshi-Nusair KM, Qudeimat MA. A prospective clinical study of mineral trioxide aggregate for partial pulpotomy in cariously exposed permanent teeth. J Endod. 2006 Aug;32(8):731-5. doi: 10.1016/j.joen.2005.12.008. 
11. Laurent $P$, Camps J, About I. Biodentine(TM) induces TGF- $\beta 1$ release from human pulp cells and early dental pulp mineralization. Int Endod J. 2012 May;45(5):439-48. doi: 10.1111/j.1365-2591.2011.01995.x.

12. Nielsen MJ, Casey JA, VanderWeele RA, Vandewalle KS. Mechanical properties of new dental pulp-capping materials. Gen Dent. 2016 Jan-Feb;64(1):44-8.

13. Kim J, Song YS, Min KS, Kim SH, Koh JT, Lee BN, et al. Evaluation of reparative dentin formation of ProRoot MTA, Biodentine and BioAggregate using micro-CT and immunohistochemistry. Restor Dent Endod. 2016 Feb;41(1):29-36. doi: 10.5395/rde.2016.41.1.29

14. Stefanova VP, Tomov GT, Tsanova STs. Morphological study of border area of pulp-capping materials and Er:YAG laser prepared hard dental surface. Folia Med (Plovdiv). 2015 JanMar;57(1):49-55. doi: 10.1515/folmed-2015-0019.

15. Nammour S, Tielemans M, Heysselaer D, Pilipili Ch, De Moor R, Nyssen-Behets C. [Comparative study on dogs between CO2 laser and conventional technique in direct pulp capping]. Rev Belge Med Dent (1984). 2009;64(2):81-6. French.

16. da Silva LA, de Freitas AC, de Carvalho FK, de Queiroz AM, Nelson-Filho P, Porto-Neto ST. Direct pulp capping with a self-etching adhesive system: histopathologic evaluation in dogs' teeth. Oral Surg Oral Med Oral Pathol Oral Radiol Endod. 2009 Jul;108(1):e34-40. doi: 10.1016/j.tripleo.2009.03.017.

17. Lu Y, Liu T, Li H, Pi G. Histological evaluation of direct pulp capping with a self-etching adhesive and calcium hydroxide on human pulp tissue. Int Endod J. 2008 Aug;41(8):643-50. doi: 10.1111/j.1365-2591.2008.01396.x.

18. Qureshi A, E S, Nandakumar, Pratapkumar, Sambashivarao. Recent advances in pulp capping materials: an overview. J Clin Diagn Res. 2014 Jan;8(1):316-21. doi: 10.7860/JCDR/2014/7719.3980.

19. Fan ML, He LB, Li JY. [Recent advances in direct pulp capping materials]. Hua Xi Kou Qiang Yi Xue Za Zhi. 2018 Dec 1;36(6):675-80. Chinese. doi: 10.7518/hxkq.2018.06.018.

20. da Rosa WLO, Cocco AR, Silva TMD, Mesquita LC, Galarça AD, Silva AFD, et al. Current trends and future perspectives of dental pulp capping materials: A systematic review. J Biomed Mater Res B Appl Biomater. 2018 Apr;106(3):1358-68. doi: 10.1002/jbm.b.33934.

21. Giraud T, Jeanneau C, Rombouts C, Bakhtiar H, Laurent P, About I. Pulp capping materials modulate the balance between inflammation and regeneration. Dent Mater. 2019 Jan;35(1):24-35. doi: 10.1016/j.dental.2018.09.008.

22. Liu J, Chen CA, Zhu X, Morrow BR, Thamma U, Kowal TJ, et al. Potential of tailored amorphous multiporous calcium silicate glass for pulp capping regenerative endodontics-A preliminary assessment. J Dent. 2021 Jun;109:103655. doi: 10.1016/j.jdent.2021.103655.

23. Pedano MS, Li X, Yoshihara K, Landuyt KV, Van Meerbeek B. Cytotoxicity and bioactivity of dental pulp-capping agents towards human tooth-pulp cells: a systematic review of in-vitro studies and meta-analysis of randomized and controlled clinical trials. Materials (Basel). 2020 Jun 12;13(12):2670. doi: 10.3390/ma13122670.

24. Alex G. Direct and indirect pulp capping: a brief history, material innovations, and clinical case report. Compend Contin Educ Dent. 2018 Mar;39(3):182-9.

25. Doumani MD, Arnous WA, Alsafadi MF, Alnazer HA, Alanazi SM, Alotaibi KS, et al. The Vital Pulp Therapy of Permanent Teeth: A Dental Practitioner's Perspective from Saudi Arabia. J Int Soc Prev Community Dent. 2020 Jun 15;10(3):300-8. doi: 10.4103/jispcd.JISPCD_69_19.

26. Lin LM, Ricucci D, Saoud TM, Sigurdsson A, Kahler B. Vital pulp therapy of mature permanent teeth with irreversible pulpitis from the perspective of pulp biology. Aust Endod J. 2020 Apr;46(1):154-66. doi: 10.1111/aej.12392. 